\title{
Biografías en movimiento: la construcción colectiva de lo biográfico a través de perfiles en dos revistas chilenas de la primera mitad del siglo $\mathrm{XX}^{*}$
}

\author{
Antonia Viu**
}

\begin{abstract}
Resumen
Al intentar comprender el lugar desde el que se articulan revistas como Claridad o Babel al interior del campo cultural chileno de la primera mitad del siglo XX, es central identificar los sentidos que lo colectivo asume para sus miembros a partir de la década del veinte. Para ello el artículo sitúa dos momentos centrales de los modos de entender lo colectivo que fundan revista Claridad en el despuntar de los años treinta y Babel durante los cuarenta. Interesa ver cómo la construcción colectiva de lo biográfico en estas revistas se arraiga en una cierta manera de entender la comunidad, que se vincula con formas de sociabilidad del anarquismo.
\end{abstract}

Palabras clave: Biografías colectivas, Babel, Claridad, carteles, anarquismo.

\section{Biographies in movement: collective construction of biographies in profiles published in two chilean magazines of the first half of the 20th Century}

\begin{abstract}
In order to understand the place of cultural magazines such as Claridad or Babel within Chilean cultural field in the first half of the 20th century, it is important to identify the meanings associated to collective endeavor among its members during this period. This article defines two key moments in the ways collectivity is understood by the members of Claridad at the beginning of the 30s and by the members of Babel during the fourties. I suggest that the collective construction of biographies in these cultural magazines is rooted in a given way of understanding community, related with sociability practices from anarchism.
\end{abstract}

Keywords: Collective biographies, Babel, Claridad, "carteles", anarchism.

\footnotetext{
* Este artículo es parte del proyecto Fondecyt regular $\mathrm{N}^{\circ} 1150141$ "Representaciones e imaginarios de la lectura en la narrativa chilena de 1940 a 1960" que dirige la autora y en el que participa Claudia Darrigrandi como coinvestigadora.

** Chilena, Doctora en Literatura Hispanoamericana por la Universidad de Chile. Académica de la Facultad de Artes Liberales de Literatura de la Universidad Adolfo Ibáñez. antonia.viu@uai.cl
} 
$\mathrm{Al}$ intentar comprender el lugar desde el que se articulan revistas culturales chilenas como Claridad (1920-1932) o Babel (1939-1951) al interior del campo cultural de la primera mitad del siglo XX, y dentro de la trayectoria de quienes las impulsaron más de cerca, es central identificar los sentidos que lo colectivo asume para sus miembros a partir de la década del veinte. Lo colectivo se articula en torno a ciertos polos de atracción que tuvieron una significativa gravitación en el período, aunque desde la historia literaria rara vez se los visibilice. Se trata de figuras concretas pero no en tanto individualidades, sino como lo que podríamos llamar, siguiendo a Giorgio Agamben en La comunidad que viene (1996) "ejemplos", un concepto que escapa al sentido moralizante que da a lo ejemplar la biografía más convencional que se publica en esos años y que sigue el paradigma de los "grandes hombres". El ejemplo funcionaría aquí, en cambio, rehuyendo la antinomia entre el universal y el particular, como "una singularidad entre las demás, pero que está en lugar de cada una de ellas, que vale por todas" (13).

En lo que sigue, pretendo identificar dos momentos centrales en los sentidos que lo colectivo asume en estas revistas: el $\mathrm{N}^{\circ} 140$ de Claridad (21 de enero de 1932), en el que varios miembros de la Generación del veinte reaccionan a la muerte de uno de sus integrantes más activos, el médico libertario Juan Gandulfo, y el $\mathrm{N}^{\circ} 28$ de $\mathrm{Babel}$ (julio/agosto de 1945), dedicado a los jóvenes del veinte, a través de varios perfiles biográficos escritos por autores que se dieron a conocer en Claridad pero que luego tuvieron una fuerte gravitación en Babel. A través de estos perfiles, escritores como los chilenos José Santos González Vera y Manuel Rojas constelan un cierto tipo de comunidad al intentar retratar a figuras como el médico libertario Juan Gandulfo, actor central en el movimiento estudiantil y en iniciativas de transformación social durante la segunda década del siglo, o a los "jóvenes de los veinte" ${ }^{1}$ durante la década del cuarenta.

Como señalábamos, un primer momento que resulta significativo en la lectura que propongo es el 21 de enero de 1932 y el Nº 140 de revista Claridad $^{2}$. Se trata del último número de la publicación que había

\footnotetext{
Como "jóvenes del veinte" se conocieron los intelectuales y escritores que circularon en torno a la Federación de estudiantes de Chile y a Revista Claridad, su principal órgano difusor. Entre los redactores de la revista estuvieron el poeta Alberto Rojas Jiménez, los médicos Juan Gandulfo y Alfredo Demaría, y los escritores José Santos González Vera y Pablo Neruda. Allí escribió también Manuel Rojas.

2 Raúl Silva Castro, uno de los fundadores de revista Claridad, relata así sus orígenes: "El día 21 de julio de 1920 se produjo, en pleno centro de Santiago, en la primera cuadra de la calle Ahumada, el asalto de
} 
funcionado desde 1920 como órgano de difusión de la Federación de Estudiantes de Chile, FECH, y que llegó a ser el emblema de los “jóvenes del veinte". Su aparición fue interrumpida en 1926 por la inminente dictadura de Carlos Ibáñez del Campo y resurgió brevemente durante 1931 para finalizar en 1932. Ese último número está dedicado en gran parte a la memoria de Juan Gandulfo. Como profesional de la salud, Gandulfo también se había destacado en sus esfuerzos por poner la atención médica al servicio de los trabajadores desde el policlínico obrero de la sección chilena de la organización sindical anarquista industrial International Workers of the World (IWW), que había llegado al país desde Estados Unidos en 1919, y como el creador de su órgano de educación y difusión más importante, el impreso La hoja sanitaria, publicado entre 1924 y 1927.

Entre los perfiles o necrológicas que escriben sobre Gandulfo autores como Sergio Atria, Santiago Ureta o Adolfo Allende, encontramos un texto de José Santos González Vera y otro de Manuel Rojas. González Vera, como ha visto el historiador Sergio Grez (2013), comienza a escribir en Claridad como colaborador "externo" desde 1921, ya que no era estudiante universitario, y lo hacía firmando con sus dos apellidos o usando seudónimos como Elías Aguirre, Demetrio Rudín o Demetrio Rubio, o incluso, solo con las iniciales G.V. El perfil que escribe sobre Gandulfo se halla junto a un gran retrato del médico en el que la beatitud de su rostro contrasta con el primer "cartel” que escribió para la revista, un exaltado llamado a la juventud a sembrar la tierra en la que nacería un pueblo nuevo: "Qué vuestras vertebras se gasten por el esfuerzo titánico del torso doblado tras la herramienta creadora" (4). El perfil de González Vera se titula “Un Juan Gandulfo”, lo que de inmediato tensiona la promesa de excepcionalidad que sugería la composición de la página, para describirlo como uno más entre otros posibles y solo a través de un punteo que recuerda una sucesión de anécdotas en las que el arrojo y generosidad que veíamos en el cartel lo ponen en situaciones incómodas y risibles.

la Federación de Estudiantes, cometido por una turba anónima [...] Roberto Meza Fuentes, director de Juventud en aquella emergencia, trató de recolectar materiales para un nuevo número de su revista, el cual vino a salir mucho después. Mientras tanto, en algunos jóvenes que estábamos a su lado, surgió la idea de lanzar pronto a la circulación una hoja de protesta, agresiva, de combate, destinada a mostrar a la opinión pública que el asalto no era suficiente para acallar a los jóvenes reunidos en la Federación de Estudiantes, y tres de ellos nos aplicamos a la tarea con tanta decisión y energía que pudimos hacerlo. Tal es, explicada en poquísimas palabras, la génesis de Claridad. Los tres éramos Alberto Rojas Jiménez, Rafael Yépez Alvear y el autor de este libro" (29). El primer número de Claridad con un artículo de Joaquín Edwards Bello aparece el día 12 de octubre de 1920, con tal éxito que se publican tres ediciones. Ver Raúl Silva Castro, "Aparición de Neruda en Claridad". 
Sin embargo esas anécdotas cumplen una función vital para mostrar la ejemplaridad de Gandulfo en el sentido que proponía más arriba. Esta no está dada por el hecho de que atendiera gratis a muchos pacientes o que les diera dinero para medicamentos, sino por la facilidad con la que se asimila a aquellos para quienes pedía una transformación social. De hecho, el perfil de González Vera muestra que Gandulfo muchas veces resulta amenazante entre pacientes que lo ven como un "roteque" ${ }^{3}$, alguien capaz de poner bombas en casas de mujeres distinguidas, de tomarse confianzas desmedidas sin que se las den o de recibir una propina en una guardarropía a un caballero que evidentemente lo toma por el encargado. Más que cualquier otra cosa, nos dice González Vera, médico eminente, caricaturista o peligroso orador, Juan Gandulfo fue obrero:

Era un obrero: Gandulfo, fuera de ser una eminencia en su profesión, poseía un talento de ricas facetas. Escribió gran parte de los carteles que figuraron en este periódico, hacía grabados en madera, dibujaba caricaturas o asuntos de utilidad científica. Siempre tenía ocupadas sus manos en una labor inteligente. En esto se parecía a un obrero, a un buen artesano. Acaso residió en su sabiduría manual el secreto de la simpatía que le unió en todo momento a los trabajadores. (4)

Como ha señalado el reciente trabajo de Nicolás Fuster y Pedro Moscoso (2015), Gandulfo como médico libertario promovió a través de la publicación periódica de "La hoja sanitaria" un saber sobre el cuerpo de corte civilizatorio que fundamentó la institucionalización y la reglamentación sanitaria que se consolidó al llegar la década del veinte en Chile y, simultáneamente, inscribió una topología del cuerpo que funcionó, desde una matriz social, como un nuevo ordenamiento que puso de relieve el autocuidado y la autogestión, un ordenamiento emancipatorio en el que las organizaciones de trabajadores como la IWW

3 Para una definición y un detallado análisis sobre la figura del roto en la literatura y en la cultura chilena, ver Claudia Darrigrandi "De héroes a vagabundos: rotos en la ciudad" (2015). Aquí cito un breve pasaje para contextualizar el uso del término en el perfil de González Vera: "En síntesis, como estereotipo de lo criollo, de la identidad mestiza, el roto ha representado las cualidades y virtudes patrias; sin embargo, la palabra "roto" también se ha utilizado peyorativamente para referirse a las personas de los grupos más bajos de la escala social, sinónimo de pobre y mal educado..." (213). Darrigrandi también cita el texto de Joaquín Edwards Bello "No existe homogeneidad de la raza": "En todo Chile ser roto o hacer roterías significa conducirse como un canalla. El roto es en general el obrero de las ciudades, el peón en general, y el gañán de los campos. Pero la clase alta cuando quiere expresar el máximun de desprecio, llama roto a cualquiera, como un insulto" (213). 
se reconocerán, adquiriendo renovado vigor, "una nueva fuerza", durante la primera mitad del siglo XX. Según Víctor Muñoz (2013), en tanto, la estructura de la IWW durante los años veinte, que agrupó a los sindicatos bajo el sistema industrialista, es decir, por rama de la producción en lugar de por oficios, le dio un impulso inédito a los trabajadores como fuerza social autogestionada, independiente del Estado.

Esta renovada consciencia de integrar un cuerpo social desde una posición autónoma es muy visible también en los personajes de los cuentos de Manuel Rojas de fines de los veinte ${ }^{4}$. Rojas, gran amigo de González Vera, siente mucha afinidad no solo con Gandulfo, sino con el colectivo que, cada vez más consistentemente, reconocerán como los jóvenes del veinte, grupo integrado por Santiago Labarca, Sergio Atria, y José Domingo Gómez Rojas. La voluntad de filiación respecto de esta formación se hace evidente en el segundo perfil sobre Gandulfo que aparece en el $\mathrm{N}^{\circ} 140$ de Claridad que aquí considero, publicado precisamente por Manuel Rojas. El perfil se llama "Mi madre, Juan Gandulfo y la muerte". De inmediato llama la atención que se diluya el suceso más contingente, la muerte de Gandulfo, con otra ocurrida dos años antes, la de la madre de Rojas, y con una serie de recuerdos anteriores que vinculan a ambos personajes con otros como González Vera.

El texto pronto deriva indirectamente en una reflexión acerca de la relación entre biografía, retrato y muerte, cuando Rojas explica por qué no visita a su madre en el cementerio:

La veía y la veo, dentro de mí, como por un objetivo fotográfico, alta, vestida de negro, rodeada de luces verdes, rojas y blancas, moviéndose como en un paisaje de jardín. Esa imagen me da la sensación que yo guardo de ella y de lo que en ella, como ser humano, amaba: sus movimientos, su color, su vida, su espíritu, en fin. Lo que está en el cementerio no es lo que yo he amado, es otra cosa, una cosa inmóvil, fría, indiferente a todo. ("Mi madre, Juan Gandulfo y la muerte" 5)

En la cita anterior, la imagen de la madre vinculada a la fotografía puede pensarse desde la definición de Paola Cortés-Rocca (2011) del retrato fotográfico como una escritura del "yo", un género que "comparte

4 El delincuente, volumen de cuentos de Manuel Rojas publicado por la Sociedad Chilena de Ediciones en 1929. 
con lo biográfico y con lo autobiográfico y lo epistolar un rasgo inicial: exhibir una subjetividad" (41). Sin embargo, para Cortés-Rocca,

una particularidad distingue el retrato fotográfico de las otras formas de escritura del yo. En el caso de esta, representar un sujeto es, fundamentalmente, representar un cuerpo y luego, representar en especial, un rostro. Tal es así que la historia del retrato fotográfico es la historia de un desarrollo técnico que permite, gradualmente, que el rostro monopolice la escena del retrato [...], un intento cuya culminación será la fotografía que certifica la identidad, un acto que funda la tarea de la criminología en la medida en que permite distinguir al delincuente del ciudadano. (41)

Es esta relación entre retrato fotográfico y criminología la que puede explicar en otro nivel el intento de estos perfiles por diluir los contornos más que por fijar al retratado. Si bien el recuerdo que Rojas hace de su madre apela a lo fotográfico, lo hace para de inmediato volverse cinético, una imagen inaprensible e incomunicable, y contribuye -de paso- a diluir el protagonismo de Gandulfo en el perfil. Tanto Gandulfo como otros jóvenes del veinte fueron encarcelados más de una vez. En 1920, por ejemplo, el médico va preso por decir que el Presidente Juan Luis Sanfuentes ${ }^{5}$ es inepto para resolver problemas sociales, como el de los trabajadores carboníferos que en ese momento estaban en huelga. Muy pronto también cae preso en lo que se conoció como el proceso contra los subversivos y en el que murió su amigo y compañero de Claridad, el poeta José Domingo Gómez Rojas. El entretejido de subjetividades que operan en los perfiles de González Vera y de Rojas, en el primer caso, como un obrero más, y en el segundo, como una imagen indiscernible de la de la madre y de él mismo, son una manera de rechazar, mediante la lógica del ejemplo, la disección social que ejerce el Estado y sus dispositivos de control. El retrato y lo biográfico solo se convocan aquí, entonces, a condición de que formen desde su singularidad la imagen de un cuerpo, el cuerpo social en su pluralidad y dinamismo, y no la de un rostro individual.

Junto a los perfiles de Juan Gandulfo que escriben González Vera y Manuel Rojas, el No 140 de Claridad inserta un texto que se titula "El

5 Quien gobierna Chile entre 1915 y 1920. 
primer cartel de Juan”. Desde un lenguaje deliberadamente poético, el fragmento de Gandulfo, elegido como homenaje, insiste en esta visión de los trabajadores como un cuerpo social:

¡Siembra, juventud! La tierra es propicia, el momento es único. Y si tu corazón estalla en la jornada noble, tu sacrificio será fecundo. No se levantará una desnuda cruz, ni una lápida estéril cubrirá tu cadáver; pero tu cuerpo de titán al sepultarse en la gran llanura, formará una montaña inmensa. Y sobre ella se erguirá el pueblo, y su cuerpo negro y deformado por la explotación, brillará como una tea anunciadora al bañarse en la luz virgen del sol de la Humanidad Futura ¡Siembra, Juventud! (4)

La importancia de esta composición, el "cartel”, en Claridad es enorme durante toda la década del veinte y es importante aquí profundizar en ella porque aunque muy diferente de un perfil, participa de la idea que hemos venido enunciando de lo biográfico desde el movimiento y desde lo colectivo. Los "carteles" de Revista Claridad protagonizaron la mayoría de las portadas de la revista durante sus doce años de vida y dan forma a una sección titulada "El cartel de hoy". El cartel como un género poético y visual que la revista cultiva tiene una relación evidente y deliberada con los carteles urbanos muy frecuentes en el comercio, en los muros de Santiago y en las huelgas obreras durante esos años. Como señala Luis Bocaz (1990), revista Claridad se caracterizó por establecer un puente entre el espacio universitario y el mundo de los obreros (443), y los interpeló desde una discursividad urbana, no como opinión pública, sino como las víctimas de un sistema a las que es necesario educar y conducir. Se trata de un lenguaje y una visión del papel del intelectual y del artista en relación al mundo de los trabajadores común en la prensa anarcosindicalista, dispositivo de la literatura anarquista durante el período, y cuyo lenguaje es muy visible en revistas como Claridad.

En efecto, como ha estudiado el argentino Pablo Ansolabahere (2011), el vínculo entre escritura, oralidad y acción, su fuerte tono interpelativo, es de hecho uno de los rasgos más señalados de la literatura anarquista. El intento de mover a la acción mediante el uso de la palabra se expresa muchas veces en poemas "declamatorios" (57). Según Ansolabahere, esto se debe a que la poética anarquista se refleja en ciertas formas propias de la literatura popular y de la inflexión oral como uno de los rasgos característicos del "trovador". Sin embargo, es importante pensar 
también en la función que cumplieron los impresos efímeros en el sistema de propaganda anarquista, para entender que este carácter interpelativo, este llamado a la acción, tiene también un claro antecedente discursivo en dispositivos como la hoja suelta y el cartel urbano. Es esto lo que justifica la necesidad de generar desde la revista una continuidad discursiva y formal con estos formatos.

Como ya señalaba, los carteles en Claridad van en la portada y son escritos por poetas, narradores e intelectuales vinculados a la revista, como los médicos Juan Gandulfo y Alfredo Demaría; el dramaturgo argentino Rodolfo González Pacheco, quien desde 1908 publicaba como "carteles" sus textos en los periódicos anarquistas trasandinos La Protesta y Antorcha; y los escritores José Santos González Vera y Pablo Neruda, aunque muchas veces tras un seudónimo; en menor medida también aparecen algunos carteles firmados por autores norteamericanos o europeos como Walt Whitman y Pío Baroja, que funcionan como citas, textos surgidos en otros contextos y fuera del ideario libertario, pero que aquí se resignifican desde el contagio con el resto de los escritos de la publicación, como a menudo ocurre en la prensa anarquista. También aparecen carteles de autoría colectiva como los que firma la Federación de Estudiantes de Chile. Así, la autoría va circulando en la sección sin que exista un criterio claro para la alternancia. Iván, por ejemplo, es la primera firma que aparece en "EL cartel de hoy" y es uno de los seudónimos de Juan Gandulfo, quien también aparecerá firmando como Juan Guerra.

Me interesa apuntar la analogía que puede establecerse entre esta forma de circulación de la autoría en la sección con el tipo de desplazamiento del cartel en una huelga o en un desfile de trabajadores, de mano en mano, y mostrando una filiación reconocible, pero colectiva y difusa, a pesar de la fuerza de la denuncia que se exhibe. La sección "El cartel de hoy", como la huelga, se impone como una forma legítima de organización para estos escritores de cara a un colectivo del que se sienten parte, como un deber ético y un desafío artístico. González Vera, uno de los escritores que más se refiere a las huelgas en la revista durante ese período, señala por ejemplo que "cualquier huelga por insignificante que sea en sus proporciones, es útil. Mantiene a la sociedad en una saludable inquietud y fomenta la ductibilidad de los organismos sociales en el sentido de identificarlos con las necesidades mínimas de la masa" ("Cómo se pierde una huelga" párr. 1). Las huelgas fomentan además la solidaridad entre los trabajadores, pero cuando fracasan también los 
ayudan a ser más escépticos respecto de las salidas formales y legales a sus conflictos. La sección de esta forma parece tomar de la huelga ambos principios: la necesidad de organizarse y el escepticismo frente al Estado y las élites.

Así, la voz del poeta y del intelectual en la sección no es solo de denuncia contra los poderosos, sino el clamor de un pueblo que se ha transformado en eco incesante y que persigue a los que pueden hablar por él, interpelando a los trabajadores que no asumen la responsabilidad de formar parte de un colectivo, engañados por la falsa autonomía que les da la etiqueta de "ciudadanos". Así lo muestra el cartel de Juan Guerra del 27 de mayo de 1922:

[...] Tú lo quieres, tú amas tu yugo y mantienes a los gobernantes de hoy y amamantas a los gobernantes de mañana. ¡Ciudadano! [sic] Ja... ja,.. ja!

¿Ciudadano...? [sic] Y por qué no productor?

¿Gobernado...? [sic] Y por qué no libre?

¡Responde! ¡Adquiere conciencia, capacítate! Porque de lo contrario, antes, durante y después de la revolución nuestro eco te gritará: Arre... arre... proletario, ciudadano, asalariado! ("El cartel de hoy. El poema al trabajo" párr. 1)

En cada cartel se reconoce una estructura común: un llamado a algún tema o actor de la coyuntura del momento que funciona como subtítulo o que simplemente abre el texto: "A los que tienen hambre y sed de justicia" se dirige el cartel anónimo del 20 de noviembre de 1920; “Miserables!” anuncia Sachka en el del 1 de septiembre de 1923, mientras que en el del 31 de octubre de 1920 se lee “¡Periodistas de Chile!”.

A continuación, sigue un texto en el que la tipografía, la diagramación y el marco imponen un cierre particular respecto del resto de la página. Junto a los textos, desfilan también semana a semana las ilustraciones firmadas por “Isaías”, “Madera de Geo”, Alberto Martini y Pedro Celedón, entre otros. El grito, el movimiento de la calle y de las huelgas, y la visualidad del cartel urbano se reproduce en estas composiciones. El personaje central suele ser el pueblo engañado por las élites explotadoras bajo la consigna inapelable de la patria, el progreso o la religión, que los lleva a sufrir el hambre o incluso la muerte en la guerra. “¡Oye, hermano: te han mentido! No solo el amor es fecundo, el odio también lo es" (párr.1), sentencia el cartel de Iván del 7 de mayo de 1921. Se trata de un 
retrato colectivo que con cada número adquiere un nuevo rasgo a partir de la denuncia y que se complementa con imágenes estilizadas de cuerpos prometeicos, sufrientes o anhelantes, tensionados por el esfuerzo que realizan y por el advenimiento de una trasformación.
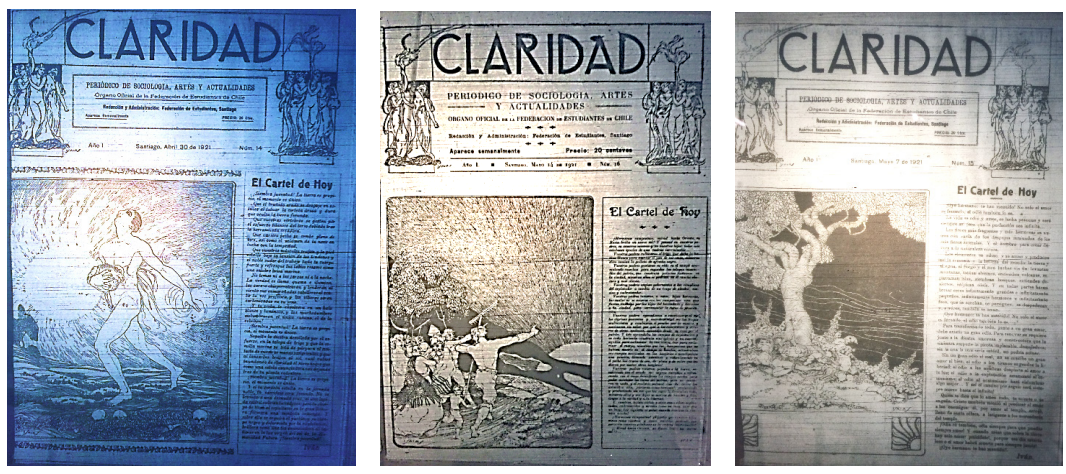

Imagen 1. Los carteles del 30 de abril, del 7 y 14 de mayo de 1921. Todos firmados por Iván e ilustrados por Isaías.

Aunque fueron muchos los ilustradores de "El cartel de hoy", en los carteles que firma Iván predomina la estética clásica de Isaías Cabezón ${ }^{6}$, con su mezcla de acanto, figuras clásicas paganas y bufonescas. Cabezón firma como "Isaías" y fue uno de los cartelistas más destacados en la década del veinte. Egresado de la Academia de Bellas Artes, sus afiches llenaban las vitrinas y las murallas de Santiago (Fuenzalida 20-21), después de que ganara reconocimiento en los concursos de afiches organizados por la FECH para la llegada de la primavera hacia fines de la década del diez (Godoy 17). Sus carteles y ornamentaciones hacen escuela en todo el país a tal punto que hasta los libros comienzan a imprimirse con una portada, un colofón o ilustraciones del cartelista. $\mathrm{Al}$ igual que en sus afiches, su diseño de colofones, capitulares y frisos en la portada de la revista, muchas veces acompañan los "carteles". Paradójicamente, se trata de una estética que a pesar de que remite a la alta cultura, tiene una resonancia visual inmediata en los trabajadores que circulan por las calles de Santiago.

6 Isaías Cabezón Acevedo (Salamanca, Chile 1891-Santiago, Chile 1963) es considerado el precursor del oficio de cartelista en Chile. Fue pintor, acuarelista, escenógrafo, curador de exposiciones e ilustrador de viñetas de libros y revistas. En 1922 viajó a Europa, donde se relacionó con importantes artistas del período. Participó en exposiciones colectivas de pintura chilena en Latinoamérica y Europa. Fue académico de la Universidad de Chile y miembro fundador de la Sociedad Nacional de Bellas Artes de Santiago, de la Federación de Artistas Plásticos de Chile y de la Asociación Chilena de Pintores y Escultores. 
Así, en el último número de Claridad los perfiles o necrológicas funcionan como la forma en que, por esos años, escritores jóvenes como Rojas o González Vera van a recordar al desaparecido Gandulfo, mostrándolo como "Un Juan Gandulfo", un intelectual que se reconoce dentro del colectivo de los trabajadores y que por lo mismo no puede ser "retratado" fuera de ese colectivo. Por otra parte, el cartel como formato remite también a Gandulfo/Iván, quien fuera uno de sus más destacados cultores en la revista, pero tampoco lo hace desde la fijeza de una imagen individual, sino desde un retrato colectivo que apela a la identificación con el lector, aquellos "hermanos" que a diario son engañados por las élites.

\section{Los jóvenes del veinte vistos desde $\mathrm{Babel}$}

En la década del cuarenta, Manuel Rojas y José Santos González Vera integran un nuevo colectivo, esta vez liderado por Ricardo Espinoza, el destacado editor y escritor que en la Argentina de los años veinte firmaba como Samuel Glusberg y que llega a Chile en 1935. Si en Claridad Rojas y González Vera habían tenido un papel secundario, en la versión chilena de Babel, que también se publicará durante doce años, entre 1939 y 1951, pero a intervalos más distanciados e irregulares y solo hasta completar sesenta números, estos serán parte del Comité Editorial de manera estable. Babel, aparece como "Revista de revistas" durante dos años y como "Revista de arte y crítica" los diez restantes, y en ella abundan los perfiles de figuras nacionales e internacionales, que cumplen una función editorial en la medida que ayudan a delinear las afinidades que unen a los colaboradores más cercanos de la revista, no sólo a José Santos González Vera, a Manuel Rojas y a Enrique Espinoza sino también a Mauricio Amster, a Ernesto Montenegro y a Luis Franco. Entre los perfiles que estos colaboradores escriben, destacan aquellos de figuras centrales del americanismo que defendía Espinoza, como José Carlos Mariátegui, ya fallecido en ese entonces, y una serie de escritores que encarnaban algo que en Babel llegó a ser fundamental: el rechazo de los nacionalismos en favor del pacifismo y la cooperación intelectual en una década marcada por la Segunda Guerra Mundial. Se trata de un americanismo que se proyectaba también en la revista en un culto a lo fronterizo que encarnaban escritores trasplantados como el mismo Espinoza, de origen judío, que llega primero a la Argentina y luego a Chile, pero también 
Horacio Quiroga, un escritor rioplatense más que de Uruguay; Guillermo Hudson, un "gringo" nacido en la pampa, o Manuel Rojas, quien para Espinoza fue siempre un escritor más trasandino que chileno o argentino.

León Trotski es uno de los personajes más gravitantes en Babel y mereció numerosos perfiles. El N ${ }^{\circ} 15 / 16$ de 1941 se dedica por completo al "solitario de Coyoacán” y en él se reúnen los que escribieron Manuel Rojas, Luis Franco, Ernesto Montenegro y Enrique Espinoza, aparte de otros autores internacionales. El de Rojas se llama "El último combatiente" y comienza estableciendo lo siguiente:

La muerte de León Trotsky pone punto final a la historia del partido bolchevique ruso. Un gran partido muere con el hombre que era su último combatiente. Con el partido y con el hombre termina, de una vez y para siempre, en todos sus aspectos vitales inmediatos, el movimiento social y político que ese partido y los hombres que lo formaban promovieron en Rusia y que tanto alcance y trascendencia ha tenido en el mundo. Empezó a declinar con la muerte de Lenin, que trajo como consecuencia el aislamiento y la persecución de Trotsky: muere definitivamente con este. (168)

El fin de la era que marca la muerte de Trotsky y la realidad de la guerra hacen que la revista mire la década del treinta con mucho escepticismo. En el $\mathrm{N}^{\circ} 2$ de 1939, por ejemplo, un texto de James T. Farrel tomado de American Mercury realiza un balance que contrasta el gran impulso revolucionario con el que los treinta habían comenzado con la agudización del fascismo y con la creciente desconfianza frente al modelo de la Unión Soviética como alternativa con que esta concluye. En el plano nacional, el Frente Popular es mirado críticamente por muchos, quienes consideran que constituye el triunfo de la clase media, pero de una clase media que no tiene consciencia alguna del problema proletario, un gobierno de "franca siutiquería", como señala Carlos Vicuña.

Desde este ánimo de fuerte decepción, el No 28 de Babel (julio/agosto de 1945) se dedicará de manera exclusiva a los jóvenes del veinte. Sin la proximidad de la muerte como pretexto, el volumen reúne perfiles escritos por los mismos protagonistas de dicho grupo ahora ya mayores, como Carlos Vicuña o Santiago Labarca, en textos que son biográficos pero explícitamente plurales: "El año veinte", "La generación del veinte" o "Juventud veinteañera". El texto de Daniel Schweitzer, en tanto, vuelve 
sobre la figura de Gandulfo. Sin embargo, no me detendré en estos textos, ya que sus autores entran en un ejercicio autobiográfico y testimonial que intenta responder preguntas como “ ¿Qué fuimos?”, “¿Qué hicimos?” o “¿Qué destruimos?”, y que por tanto nos alejarían de un análisis de las formas que asume específicamente lo biográfico. Más relevante me parecen, en este trabajo, analizar los textos de los babelianos, que miran a los jóvenes de los veinte, desde una identificación clara, pero también desde el nuevo proyecto que constituye Babel, como ocurre en el caso de González Vera y Manuel Rojas. La identificación con ellos sigue siendo evidente, de hecho Espinoza escribe un colofón que le permite filiarse también, a pesar de no haber vivido en Chile en aquella época, al señalar que fueron los jóvenes de los veinte los más entusiastas suscriptores internacionales de la Babel argentina de esos años, lo que lo insertaría, pese a su lejanía de Santiago, en una temprana comunidad intelectual con los chilenos.

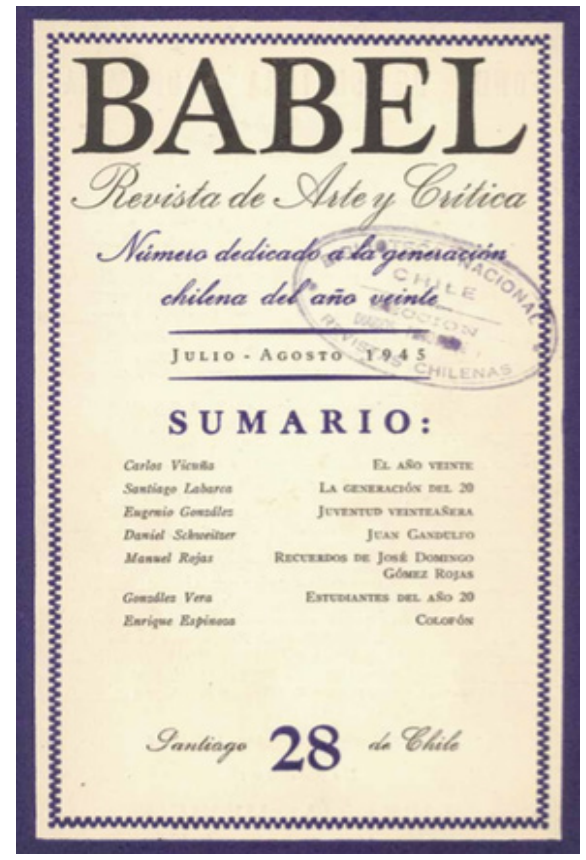

Imagen 2. Portada del №28 de Babel de julio-agosto de 1945. Dedicada a la generación chilena de 1920.

En este número, el perfil de Manuel Rojas está dedicado a José Domingo Gómez Rojas, uno de los fundadores de Claridad, un joven poeta, el mártir por excelencia de la violencia vivida por los estudiantes 
de los años veinte. Llama la atención que dicho perfil no se centre en lo injusto de su muerte, sino más bien que en un nivel más alegórico sugiera que esta habría sido inevitable por entonces ya que, como escritor, su poesía se hacía cada vez más estetizante, alejándose de la sensibilidad de los trabajadores. De esta forma, la literatura implicaría una muerte anticipada para el poeta que se vuelve demasiado individual, que inevitablemente deja de integrar una comunidad de clase. Por otra parte, el perfil de González Vera, "Estudiantes del año veinte”, ya ha dejado por completo el tono humorístico de Claridad y se centra también en los principales hechos de violencia de dicho año, cuando ocurre el ataque a la sede de la Federación de Estudiantes de Chile y Gandulfo cae preso. González Vera es parte de quienes defienden la FECH y el perfil se transforma en una crónica minuto a minuto de lo ocurrido en ese momento.

Me parece interesante que ambos textos, en su descripción de las situaciones de violencia que enfrentaron los estudiantes, subrayen los sacrificios y el heroísmo personal, lejos de lo que hicieron en sus perfiles de 1932 con Gandulfo, pero también que al evocarlos trece años más tarde construyan una retórica del antes y del después. Si Trotsky es el último combatiente del partido bolchevique, los jóvenes del veinte parecen ser ahora los últimos combatientes para quienes la adhesión a una idea justificaba la acción exaltada al punto de sufrir la muerte o la prisión. Lo que se esboza aquí, para volver a Agamben, es un colectivo que marca una distancia insalvable respecto de lo que unió a quienes fueran sus precursores y que en el presente, en cambio, se articula desde la posibilidad de una comunidad sin fundamento o impolítica; en un momento en que los totalitarismos han mostrado su disposición a hacer de todos virtuales homines sacri, una comunidad que solo busque una pertenencia contingente y no fundada parece ser el proyecto más claro de la revista que, desde su título y sus editoriales, apela a la fundación de un espacio en que todas las lenguas tengan cabida, un espacio polémico, pero que no intenta ser ideológico ni representativo. La peculiar versión de esta comunidad sin fundamento en Babel tiene que ver con un ámbito que congrega pero que al mismo tiempo disuelve, un lugar que reúne en un no saber aún, en un no querer ser ni hacer, un espacio muy diferente al que congregó a los jóvenes de los veinte.

Se trata de un colectivo que a pesar de las férreas convicciones de parte de sus miembros en tiempos de Claridad, en la década del cuarenta 
muestra sentimientos bastante menos radicales, el pacifismo, un deseo de integración de los países latinoamericanos y una visión común de la cultura, pero que se articula más bien desde ciertos rechazos, como el que sostienen, por ejemplo, contra el humanismo que profesan intelectuales como Jacques Maritain. Los textos del filósofo personalista francés, muy en boga durante esos años a raíz de la publicación y traducción al español de su libro Humanismo integral en 1936, se construyen sobre una idea de persona capaz de reconstruir la conexión entre sujeto y derecho tras los totalitarismos del siglo XX.

En el N 12 de 1940 de Babel se publica un artículo de Sidney Hook, un filósofo pragmatista norteamericano, que resulta elocuente como diagnóstico del impacto de las ideas de Maritain en el período:

El peligro de las ideas de M. Maritain es hoy mayor que nunca. La desmoralización de los movimientos radicales y socialistas en todo el mundo, única consecuencia indiscutida del stalinismo, brinda a M. Maritain su gran oportunidad. Muchos de los literatos profesionales se han vuelto ya a sus torres de marfil, de las que las había sacado la depresión para arrojarlos indefensos al torbellino doctrinal. Unos pocos, los más inteligentes y de mayor integridad moral han acabado por dedicarse al cultivo de un espiritualismo cuya consecuencia lógica, en un Tolstoi como en un Aldous Huxley, es el retiro, no solo de la política, sino también del mundo. Para aquellos a quienes Hitler y Stalin no han amedrentado, obligándolos a pactar con el capitalismo, el "humanismo integral" de M. Maritain se presenta hoy como la única alternativa aparente de un socialismo democrático... (73)

Para Maritain, según Hook, los ideales del marxismo no son objetables, sino solo su base metafísica, su ateísmo, y la gran atracción que provoca radicaría en hacer que eso parezca posible, como si la metafísica de un sistema doctrinario fuera separable de sus ideales. Esta ilusión de diferencia es la que defiende Maritain desde un catolicismo que teme que la soberanía absoluta de la colectividad desembarazada de Dios desemboque en la negación de la persona tal y como él la entiende, es decir, "lo que mantiene una parte del cuerpo sometida a otra en la medida que hace de esta el sujeto de la primera. Que somete al ser vivo a sí mismo" (Espósito 65). El hombre es persona solo si es dueño de su parte animal, dice Maritain, lo que parece despertar para los miembros 
de Babel tantas dudas como para Roberto Espósito, quien ve en este concepto un dispositivo que más que resolver la fractura entre sujeto y vida a través del derecho, la genera: "la noción de persona no está en condiciones de subsanar el extraordinario hiato entre vida y derecho, entre nomos y bios, porque es ella misma la que la produjo" (59).

El análisis de Claridad y Babel a partir de los perfiles propuestos permite entender las diferentes nociones de lo colectivo que animan, por una parte, a la juventud de los años veinte, de la que participan de manera menos central José Santos González Vera y Manuel Rojas, y, por otra, aquella que los articula al integrar el colectivo Babel a partir de 1939. Si hay muchas prácticas de asociatividad y formas de entender lo colectivo de raíz anarquista que persisten en Babel, la revisión de los perfiles estudiados muestra que hay un aspecto central de lo colectivo que se redefine tras la década del treinta, con el avance de los totalitarismos, la guerra y la desaparición de los líderes que encarnaron proyectos de sociedad relevantes para sus miembros, como Juan Gandulfo desde el anarcosindicalismo. Una retórica del antes y del después que desplaza cualquier posibilidad de activismo político en el presente y que reemplaza la audacia, como valor supremo en los perfiles de los años veinte por una comunidad que en los cuarenta va a expresarse como anhelo de resistencia pacífica, proximidad y cooperación. El estudio de perfiles en la primera mitad del siglo XX desde un foco acotado permite de esta forma acercarse dinámicamente a lo biográfico para advertir cómo el relato de una vida se redefine desde las embestidas que lo colectivo impone tempranamente a la persistencia del sujeto humanista.

\section{Referencias bibliográficas}

Agamben, Giorgio. La comunidad que viene. Madrid, Pre-textos, 1996.

Anónimo. "El Cartel de Hoy". Claridad [En línea], vol. 1, no. 7, 20 noviembre 1920, s.p. Web. 11 ene. 2017.http://www.claridad. uchile.cl/index.php/CLR/article/view/10032/10082

“El Cartel de Hoy". Claridad [En línea], vol. 1, no. 4, 31 octubre 1920, s. p. Web. 11 ene. 2017 http://www.claridad.uchile.cl/index. $\mathrm{php} / \mathrm{CLR} /$ article/view/6357/6210

Ansolabahere, Pablo. Literatura y anarquismo en Argentina (1879-1919). Rosario, Beatriz Viterbo Editora, 2011. 
Bocaz Luis. "La revista Claridad: acerca de su significación en la historia cultural de Chile". América : Cahiers du CRICCAL, no. 4-5, 1990, pp. 441-460.

Cortés-Rocca, Paola. El tiempo de la máquina. Retratos, paisajes y otras imágenes de la Nación. Buenos Aires, Editorial Colihue, 2011.

Espósito, Roberto. “El dispositivo de la persona”. Buenos Aires/Madrid, Amorrortu Editores,

Farrel, James T. "El final de una década”. Babel, no. 9, 1939, pp. 259.

Darrigrandi Navarro, Claudia. “De héroes a vagabundos: rotos en la ciudad" Huellas en la ciudad: figuras urbanas en Buenos Aires y Santiago de Chile, 1880-1935. Santiago, Cuarto Propio, 2015.

Fuenzalida, Héctor. El artista Isaías Cabezón. Santiago, Editorial Universitaria, 1960.

Fuster Sánchez, Nicolás y Pedro Moscoso-Flores (comp.). La hoja sanitaria. Archivo del

policlínico Obrero de la I.W.W., Chile 1924-1927. Santiago, Ceibo, 2015.

Godoy, Alejandro. Historia del afiche chileno. Santiago, Universidad Arcis, 1992.

González Vera, José Santos. “Un Juan Gandulfo”. Claridad, vol. 9, no. 140, 21 enero 1932, pp. 4.

_. “Como se pierde una huelga”. Claridad [En línea], vol. 1, no. 26, 21 de julio 1921, s. p. Web. 11 ene. 2017. http://www.claridad.uchile. cl/index.php/CLR/article/view/6805/6643

_.."Estudiantes del año veinte”. Babel, no. 28, Julio- agosto 1945, pp. 34.

Grez, Sergio. “González Vera: De muchacho anarquista a hombre de izquierda”. Anales de Literatura Chilena, no 14, 19, Junio de 2013, pp. 183-210.

Guerra, Juan. “El Cartel de Hoy. El Poema al Trabajo.” Claridad [En línea], vol. 2, no. 53, 27 de mayo 1922, s.p. Web. 11 ene. 2017. http://www.claridad.uchile.cl/index.php/CLR/article/ view/9916/9966

Hook, Sidney. "El humanismo integral de Jacques Maritain". Babel, no.12, 1940, pp. 72-75.

Iván. "El Cartel de Hoy”. Claridad, vol. 1, no.16, 30 abril 1921, s. p. 
. "El Cartel de Hoy". Claridad [En línea], vol. 1, no.15, 7 mayo 1921, s. p. Web. 11 ene. 2017. http://www.claridad.uchile.cl/index. $\mathrm{php/CLR/article/view/9841/9891}$

. "El Cartel de Hoy”. Claridad, vol. 1, no. 16, 15 mayo 1921, s. p.

. “Juan Gandulfo. El primer cartel de Juan”. Claridad, vol. 9, no. 140, 21 enero 1932, pp. 4.

Labarca, Santiago. “La generación del 20”. Babel, no. 28, julio-agosto de 1945, pp. 11-12.

Muñoz, Víctor. Cuando las bombas son de papel. El Estado y la propaganda anarquista

impresa. (Región chilena, 1915-1927). Talca, Ediciones Acéfalo, 2013.

Rojas, Manuel. El Delincuente. Santiago, Sociedad Chilena de Ediciones, 1929.

_.. "Mi madre, Juan Gandulfo y la muerte". Claridad, vol. 9, no. 140, 21 enero 1932, pp. 5-6.

___. "El último combatiente”. Babel, no.15-16, enero- abril 1941, pp. 168-170.

Sachka. “El Cartel de Hoy. ¡Miserables!”. Claridad [En línea], vol. 4, no. 103, 1 septiembre 1923, s. p. Web. 11 ene. 2017. http://www. claridad.uchile.cl/index.php/CLR/article/view/9424/9474

Schweitzer, Daniel. “Juan Gandulfo”. Babel, no. 28, julio-agosto de 1945, pp.18-24.

Silva Castro, Raúl. “Aparición de Neruda en Claridad”. Pablo Neruda. Santiago, Editorial

Universitaria 1964.

Vicuña, Carlos. “El año veinte”. Babel, no. 28, julio-agosto de 1945, pp. 3-10. 